\title{
IMUNOGENICIDADE E POTENCIAL VACINAL DAS \\ FLAGELINAS DE Salmonella enterica sorovar Typhimurium
}

Tese apresentada ao Instituto de Ciências Biomédicas da Universidade de São Paulo, para obtenção do Título de Doutor em Ciências.

Área de concentração: Microbiologia

Orientador: Prof. Dr. Luís Carlos de Souza Ferreira

Co-orientadora: Dra. Maria Elisabete Sbrogio de Almeida

SÃO PAULO 


\section{RESUMO}

Massis LM. Imunogenicidade e potencial vacinal das flagelinas de Salmonella enterica sorovar Typhimurium [tese]. São Paulo: Instituto de Ciências Biomédicas da Universidade de São Paulo; 2007.

Flagelina, a subunidade estrutural dos flagelos bacterianos, pode ser empregada em estratégias vacinais como carregadora de epitopos antigênicos fusionados ou como adjuvante, co-administrada por vias de mucosa ou parenteral. Tais características estão associadas à propriedade das flagelinas bacterianas em ativar mecanismos de respostas dos sistemas imunológicos inato e adquirido. Linhagens de Salmonella enterica expressam centenas de tipos flagelares distintos sendo que linhagens pertencentes ao sorovar Typhimurium expressam dois tipos flagelares: FliCi (fase 1), codificada pelo gene fliCi, e FljB (fase 2), codificada pelo gene fljB. Neste trabalho avaliamos a imunogenicidade e o potencial vacinal das flagelinas Salmonella enterica sorovar Typhimurium em camundongos BALB/c após administração pelas vias oral ou intraperitoneal. Utilizamos linhagens vacinais derivadas de $S$. Typhimurium SL3261 aroA modificadas geneticamente para expressar apenas um tipo flagelar. A partir deste modelo avaliamos as respostas de anticorpos, sistêmicos ( $\operatorname{lgG}$ ) e secretados ( $\lg A)$, e celulares (ativação de linfócitos T CD4 ${ }^{+}$e $\mathrm{TCD}^{+}$) antiflagelina nos animais submetidos a diferentes regimes vacinais. Avaliamos também o potencial adjuvante das flagelinas após co-administração por via nasal com a fímbria CFA/l, expressa por linhagens de Escherichia coli enterotoxigênica (ETEC).

Os resultados indicam que animais imunizados pela via oral com linhagens flageladas de $S$. Typhimurium não desenvolvem respostas de anticorpos, sistêmicos ou secretados, anti-flagelina. Por outro lado, animais imunizados com linhagens atenuadas de $S$. Typhimurium ativam respostas celulares específicas para as flagelinas em função da via de administração utilizada. Observamos ainda que as diferentes flagelinas testadas apresentam efeito adjuvante quando co-administradas pela via nasal com a fímbria CFA/I de ETEC. Em suma, os resultados apresentados contribuem para um melhor conhecimento sobre as propriedades imunológicas e adjuvantes das flagelinas de $S$. Typhimurium e agregam informações para o uso racional dessas proteínas em formulações vacinais.

Palavras-chave: Salmonella Typhimurium atenuada, Antígenos Heterólogos, Flagelina, Resposta Imune, Adjuvantes, Vacinas de mucosa. 


\begin{abstract}
Massis LM. Immunogenicity and vaccine approach of Salmonella enterica sorovar Typhimurium flagellins. [Ph. D. Thesis]. São Paulo: Instituto de Ciências Biomédicas da Universidade de São Paulo; 2007.
\end{abstract}

Flagellin, the structural subunit of bacterial flagella, can be used in vaccine development as a fused antigenic epitope carrier or as an adjuvant. It can either be co-administrated through mucosal or parenteral route. These features regard flagellin properties which activate response mechanisms of both innate and acquired immunological systems. Salmonella enterica strains express many different flagellar types. Among these, strains belonging to serovar Typhimuirum express two flagellar types: FliCi (phase 1), coded by fliCi gene, and FljB (phase 2), coded by fljB gene. In this work we evaluated the immunogenicity and vaccine approach of $S$. Typhimurium flagellin in BALB/c mice after administration by oral or intraperitoneal route. Vaccine strains derivatives from S. Typhimurium SL3261 aroA were genetically modified to express only one flagellar type, which enabled us to evaluate specific anti-flagellin responses in mice, including serum $(\lg G)$ and secreted $(\lg A)$ antibody response and also cellular response $\left(\mathrm{T} \mathrm{CD}^{+}\right.$e $\left.\mathrm{TCD}^{+}\right)$. In addition, the adjuvant approach of flagellin after co-administration with CFA/l fimbriae (expressed by Escherichia coli enterotoxigenic strains (ETEC)) by nasal route was also accessed. Our results indicate that mice immunized by oral route with flagellated $S$. Typhimurium strains do not develop any anti-flagellin antibody response, be it serum or secreted. On the other hand, specific anti-flagellin cellular response was observed depending on the chosen route of immunization with $S$. Typhimurium attenuated strain. Furthermore, all flagellins tested proved to be efficient adjuvants when co-administrated with CFA/I fimbriae by nasal route. Together, these results contribute to a better understanding of the immunological and adjuvant properties of $S$. Typhimurium flagellins and also provide information on the rational use of these proteins in vaccine development.

Keywords: Attenuated Salmonella Typhimurium, Heterologous Antigens, Flagellin, Immune Response, Adjuvants, Mucosal Vaccine. 


\section{INTRODUÇÃO}

As bactérias do gênero Salmonella são patógenos intracelulares facultativos, capazes de ter acesso às camadas subjacentes ao epitélio intestinal. Tal propriedade permite que esses microrganismos alcancem os tecidos mais profundos e escapem de mecanismos de defesa do hospedeiro (Ramos et al., 2004). O processo de invasão é complexo, envolve uma íntima interação entre a bactéria e a célula do hospedeiro, com possível troca de sinais bioquímicos.

A nomenclatura em Salmonella é complexa e pesquisadores usam diversos sistemas para citar esse gênero, porém, a uniformidade na nomenclatura de Salmonella é necessária. Atualmente, é aceita a subdivisão em duas espécies: Salmonella enterica e Salmonella bongori. A espécie Salmonella enterica, por sua vez, possui uma grande variedade de sorovares - grupos de linhagens que compartilham antígenos de superfície reconhecidos por anticorpos específicos - em função de suas características antigênicas somáticas (antígeno O) e flagelares (antígeno H) (Tabela 1), que são designados após a subespécie ou após o gênero tais como: Enteritidis, Typhimurium, Typhi, Dublin, Müenchen e outros (Brenner et al., 2000) (Tabela 1).

Tabela 1 - Classificação de alguns sorovares de Salmonella em função da expressão de antígenos somáticos e flagelares

\begin{tabular}{l|l|l|l}
\multicolumn{1}{c|}{ SOROVARES } & \multicolumn{2}{|c|}{ SOMÁTICO } & \multicolumn{2}{c}{ FLAGELAR } \\
\hline & \multicolumn{2}{|c}{ AgO } & \multicolumn{2}{c}{ AgH } \\
\cline { 3 - 4 } & & Fase1 & Fase2 \\
\hline S. Dublin & $1,9,12(\mathrm{Vi})$ & $\mathrm{g}, \mathrm{p}$ & ------ \\
\hline S. Müechen & 6,8 & $\mathrm{~d}$ & 1,2 \\
\hline S.Typhi & $9,12(\mathrm{Vi})$ & $\mathrm{d}$ & ------ \\
\hline S. Enteritidis & $1,9,12$ & $\mathrm{~g}, \mathrm{~m}$ & 1,7 \\
\hline S. Typhimurium & $1,4,5,12$ & $\mathrm{i}$ & 1,2
\end{tabular}

Existe diferentes sovares que causam doença ao homem e aos animais. Alguns sorovares são hospedeiro-específico, infectam apenas uma espécie, causando doença sistêmica grave como, por exemplo, $S$. enterica Typhi (ou $S$. Typhi) e S. enterica Paratyphi (S. Paratyphi), responsáveis pela febre tifóide e entérica ou paratifóide em humanos, respectivamente. Outros sorovares têm um amplo número de hospedeiros e podem causar doença sistêmica em roedores e 
animais domésticos, como o caso da $S$. Typhimurium que causa a febre tifóide murina (Weinstein et al., 1998).

Os sorovares $S$. Typhi e $S$. Typhimurium são eficientes patógenos entéricos e invadem células do epitélio viloso e placas de Peyer com posterior proliferação em tecidos linfóides do intestino. Tanto $S$. Typhi como $S$. Typhimurium aderem seletivamente à superfície das células $\mathrm{M}$ nas placas de Peyer e provocam alterações morfológicas, na face apical da célula, seguidas por degeneração celular e acesso das bactérias às camadas mais profundas da mucosa intestinal (Neutra et al., 1996; Siebers \& Finlay, 1996). Essa capacidade de aderir às células $M$ e atingir alvos mais internos, com subseqüente ativação de respostas imunológicas diversas, tem sido explorada para o desenvolvimento de linhagens atenuadas, usadas como vacinas orais (Chatfield et al., 1989; Manganaro et al., 1994; Savidge, 1996; Slauch et al., 1997).

Durante os últimos 30 anos, diversas linhagens atenuadas de Salmonella foram construídas como vacinas contra febre tifóide para administração oral. 0 microrganismo atenuado persiste por um período de tempo prolongado in vivo e interage com o hospedeiro, mimetizando o processo infeccioso desenvolvido por linhagens selvagens. Essa permanência do microrganismo no hospedeiro permite a ativação de respostas imunes celulares, humorais e citotóxicas (Dogget e Brown, 1996).

Linhagens de Salmonella são caracteristicamente patogênicas aos seus hospedeiros e derivados avirulentos não são encontrados na natureza. A administração de 100 a 500 bactérias é suficiente para a geração de quadros sintomáticos como a febre tifóide e as gastroenterites tanto em humanos como em animais (Hess \& Kaufmann, 1996). Acredita-se que cerca de 200 a 500 genes sejam necessários para que linhagens de Salmonella causem doença a seus respectivos hospedeiros. (Heithoff et al., 1999, Bäumler, 1997). Portanto, a obtenção de variantes atenuados depende da obtenção em laboratório de mutações que inativem genes, direta ou indiretamente, envolvidos com a capacidade de causar doença sem o comprometimento da imunogenicidade, essencial para uma resposta profilática efetiva.

Diversas mutações atenuadoras foram obtidas em Salmonella e em geral, levam ao aumento da dose letal para valores superiores a $10^{9}$ bactérias em modelos animais. Estas mutações foram agrupadas em três grandes grupos em função dos 
genes envolvidos: mutações que afetam genes envolvidos na virulência, mutações em genes do metabolismo biossintético e mutações em genes que codificam proteínas reguladoras da expressão gênica. Dentre o grupo das mutações de genes do metabolismo biossintético, mutações nos genes aro demonstraram estáveis e atenuadoras (Hormaeche et al., 1991).

Os genes aro, usualmente inativados para a atenuação de linhagens de Salmonella, são o $\operatorname{aro} A$, $\operatorname{aroC}$ e $\circ$ aroD. Algumas dessas linhagens são utilizadas como protótipos de vacinas bivalentes, como a SL3261 de S. Typhimurium, a SL5930 de S. Dublin e a linhagem CVD908 de S. Typhi (Hoiseth \& Stocker, 1981, Newton et al., 1989, Stocker \& Newton, 1994, Garmory et al., 2002). Uma vez administradas por via oral ou parenteral, linhagens de Salmonella deficientes em genes aro podem persistir nos tecidos do hospedeiro por alguns dias mas são eliminadas sem causar qualquer seqüela ou sintoma.

A utilização de linhagens atenuadas de $S$. Typhi na vacinação contra a febre tifóide levou muitos pesquisadores a investigar o potencial dessas bactérias como veículo para expressão e apresentação de antígenos heterólogos oriundos de outros patógenos ao sistema imune de mamíferos (Chatifield et al., 1994, Hormaeche et al., 1995). Diversos grupos de pesquisadores têm arquitetado a expressão de antígenos heterólogos em fusão com diferentes proteínas bacterianas visando o reconhecimento pelo sistema imune e a indução de resposta celular ou humoral na dependência da via e do esquema de imunização, da compartimentalização do antígeno expresso e da quantidade de antígeno apresentado ao sistema imune (Garmory et al., 2002). Essa abordagem consiste na clonagem de epitopos de interesse dentro de sítios permissíveis de uma proteína receptora. Um sítio permissível é aquele que permite a inserção de um peptídeo sem perda da maioria das propriedades biológicas da proteína receptora. As principais proteínas utilizadas nestas construções são: LamB- Proteína da membrana externa; MalE- proteína periplasmática solúvel ; OmpC- proteína da membrana externa; Pilina- proteína que compõe a fímbria e Flagelina- proteína que compõe o filamento flagelar.

O sistema Salmonella-Flagelina emprega a flagelina de Salmonella, a subunidade estrutural do flagelo, para a fusão e apresentação de epitopos heterólogos. A possibilidade de usar o flagelo como transportador de epitopos surgiu em função da elevada imunogenicidade do flagelo bacteriano; grande variabilidade de antígenos flagelares na natureza, o que sugere grande permissividade para a 
inserção de seqüências heterólogas; e a presença de uma região central hipervariável capaz de acomodar seqüências heterólogas (figura 1) (Joys et al., 1985, Joys, 1991; Wei et al., 1985; Stocker, 1990). A variabilidade da região central e o fato de que substituições de aminoácidos e deleções 'em fase' nessa região não alteram a função flagelar, sugeriram que a inserção de seqüências de interesse seria uma estratégia para expressão de antígenos heterólogos com interesse vacinal (Newton et al., 1989; He et al., 1994).

Os terminais amino e carboxi das flagelinas de Salmonella, ao contrário da região central, são bem conservados entre os diferentes sorovares. Análises recentes da estrutura da flagelina flagelina de Salmonella revelaram que o filamento flagelar é montado pela sobreposição dos monômeros pelos terminais amino e carboxi enquanto que a porção central da flagelina fica exposta na superfície do filamento (Yonekura et al., 2003). Epitopos reconhecidos para anticorpos gerados contra flagelina estão localizados na região central e explicam a base da diversidade detectada pela sorotipagem (Joys e Schodel, 1991). As regiões terminais formam estruturas a-hélices, denominadas domínios D0 e D1 enquanto que a região central tem como estrutura prevalente folhas $\beta$ pregueadas e foram denominadas domínios D2 e D3 (Yonekura et al., 2003). 


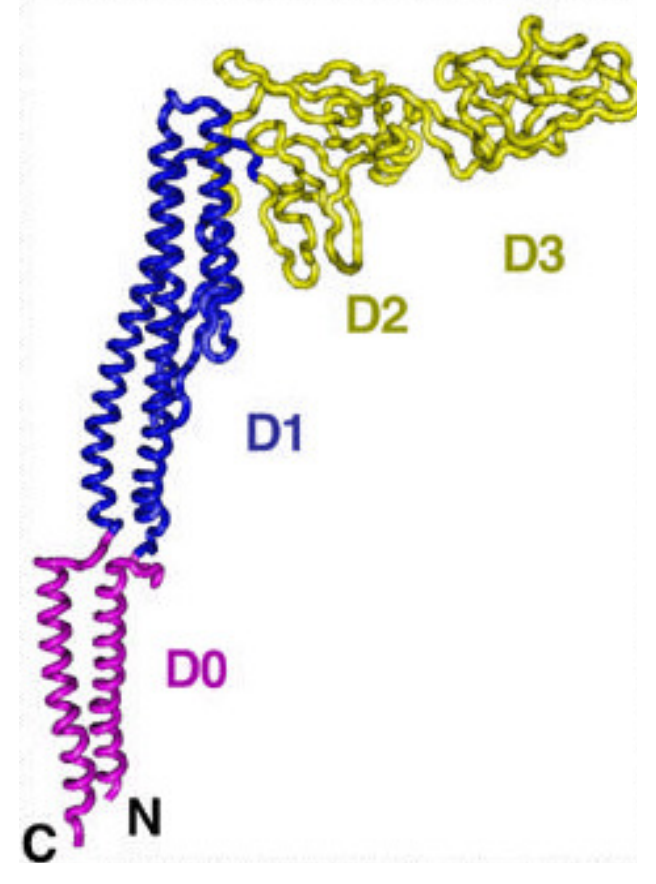

Figura 1- Estrutura do monômero de flagelina. Os segmentos D0 a D3 foram definidos por Yonekura et al. (2003), de acordo com a homologia entre os diferentes genes de flagelina $(a, c, d, i)$. O dominios D0 e D1 correspondem à região conservada da flagelina e os domínios D2 e D3 representam a região hipervariável (reproduzido de Ramos et al., 2004).

Em Salmonella, a correta montagem do flagelo requer cerca de 50 produtos gênicos arranjados em 17 óperons divididos de acordo com a ordem em que são expressos. Os produtos dos genes reguladores de classe I, flhD e flhC controlam positivamente a transcrição dos genes da classe II, muitos dos quais codificam componentes necessários para o estágio inicial de montagem do corpo basal. Um dos genes ativados codifica um fator de iniciação que aciona os genes de classe III que são específicos para a montagem do filamento flagelar. Essa organização temporal coincide com as etapas de formação do flagelo funcional (Aizawa, 1990; Wilson et al., 1993; Hughes et al.,1993).

Algumas linhagens de Salmonella ainda apresentam um mecanismo de variação de fase flagelar, como em $S$. Typhimurium, que consiste em um processo em que a presença do repressor FljA impede que haja expressão do gene fliCi. Este repressor é codificado pelo gene fljA, que está localizado em um óperon no qual também está localizado o gene fljB responsável pela expressão do flagelo FljB. Logo, quando esses genes são transcritos ocorre a repressão de FliCi. Adjacente à região de $f j j A / f l j B$ encontra-se o gene hin que codifica a recombinase Hin, que 
provoca a inversão reversível de um segmento de 993 pares de bases do cromossomo. Esse segmento, que muda de orientação alternando entre dois estados possíveis, contém o gene hin e o promotor do óóperon $f j j A / f j B$, ladeados pelas repetições invertidas hixL (à esquerda) e hixR (à direita). O óperon fljA/fljB só pode ser transcrito quando conectado a seu promotor. Logo, a orientação do segmento de $933 \mathrm{pb}$ controla a expressão da unidade de transcrição $f l j A / f l j B$, pois pode desconectá-la de seu promotor. Neste caso, a expressão do gene flic fica desbloqueada. Por outro lado, o gene hin pode expressar-se em qualquer das orientações do segmento, uma vez que está sempre conectado ao seu promotor (Figura 2) (Bonifield \& Hughes, 2003).
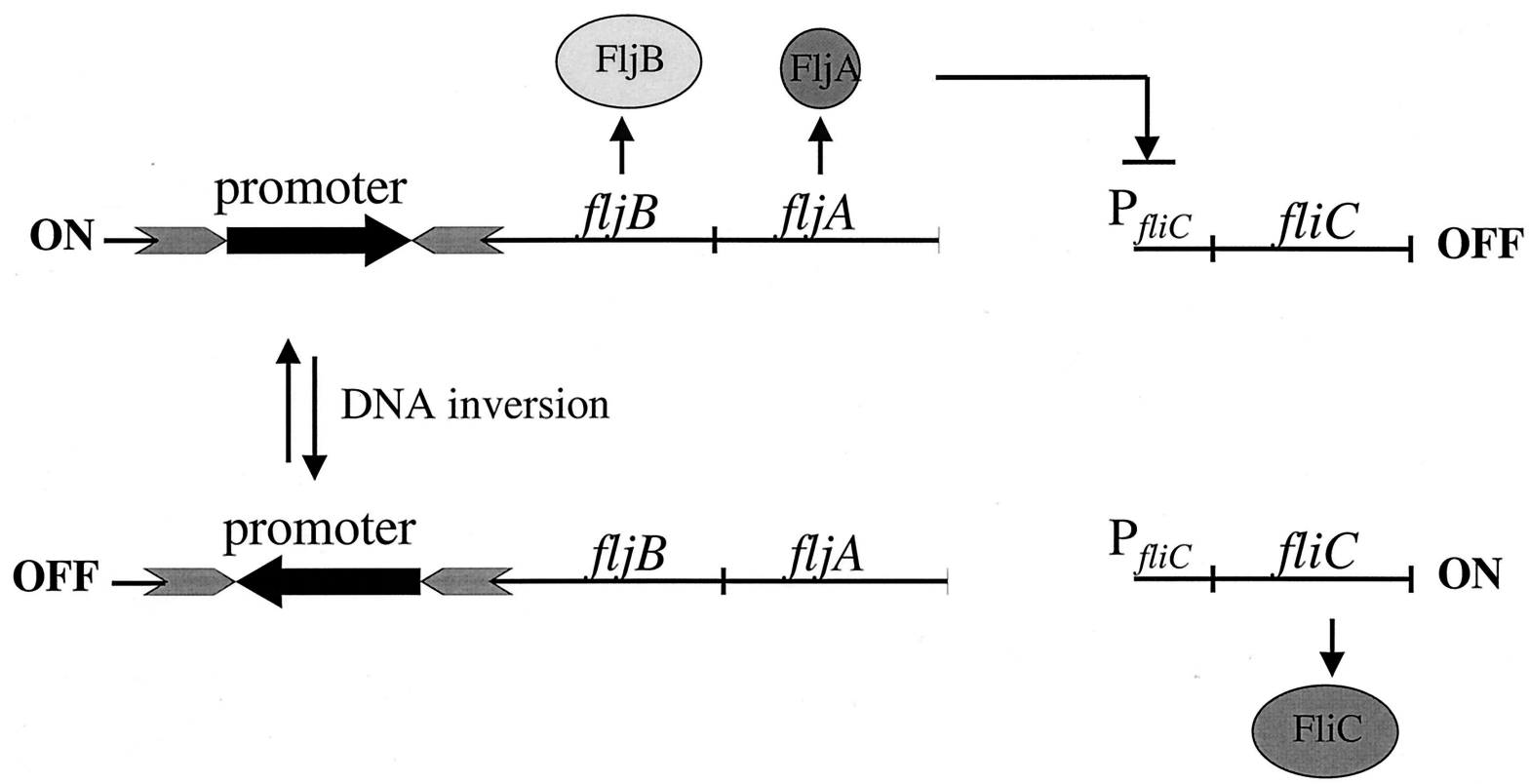

Figura 2- Representação esquemática do mecanismo de variação de fase em $S$. Typhimurium (reproduzido de Bonifield and Hughes in Journal of Bacteriology, 2003).

As pesquisas em flagelina têm crescido devido a descobertas recentes sobre o papel dessa molécula sobre o sistema imunológico de mamíferos. Os produtos microbianos reconhecidos pelo sistema imune inato são membros de uma família de padrões moleculares associados ao patógeno (PAMPs - pathogen-associated molecule patterns), moléculas usadas pelo hospedeiro mamífero para detectar a invasão por patógenos de origem microbiana. A habilidade do sistema imune inato em reconhecer e responder para componentes bacterianos e virais tem sido atribuída a uma família de proteínas transmembrana chamadas de receptores Tolllike (TLRs) (Basset et al., 2003; Marciani, 2003; Michalek et al., 2002; Takeda et al., 
2003). Estudos têm demonstrado que os TLRs podem ser expressos por uma grande variedade de células do hospedeiro, incluindo as células apresentadoras de antígenos (APC), como monócitos/macrófagos e células dendríticas (CDs) (Basset et al., 2003; Muzio et al., 2000).

O reconhecimento de produtos microbianos pelos receptores TLRs pode levar à ativação de uma variedade de mecanismos de transdução de sinais e uma indução subseqüente de citocinas e moléculas co-estimuladoras (Lien \& Golenbock, 2003; Marciani et al., 2003). A capacidade dos produtos microbianos de interagir com os receptores TLRs específicos, expressos por células apresentadoras de antígenos, tem sido explorada em pesquisas vacinais, em função da propriedades adjuvantes expressas por alguns desses compostos (Marciani et al. , 2003; Martin et al., 2002). Em mamíferos são encontrados 10 TLRs e, entre eles, está o TLR5, o qual se liga a flagelina por meio da região conservada, induzindo maturação de CD humanas e murinas (Datta et al., 2003; Didierlaurent et al., 2004; Tsujimoto et al. 2005) e a produção de citocinas, quimiocinas e óxido nítrico por monócitos e CDs (Didierlaurent et al., 2004, Means et al., 2003, Smith et al., 2002, Hayashi et al., 2001, Mizel et al., 2003).

Tratamentos baseados na administração parenteral com flagelina estimulam a liberação de mediadores pró--inflamatórios como TNF-a, interleucina 1(IL-1), IL-6, IL8 e óxido nítrico (NO) (Ciacci et al., 1998; Ciacci et al., 1999; Mizel et al., 2003). Além disso, essa proteína ativa também o sistema imune adaptativo (Honko e Mizel, 2005; Huleatt, et al., 2007), pois flagelina é um dos principais alvos de respostas mediadas por células T CD4+ (McSorley et al., 2000, Gewirtz, et al., 2001). Essa propriedade faz dessa molécula uma interessante ferramenta no desenvolvimento de estratégias vacinais.

A primeira experiência utilizando o sistema de apresentação de antígeno heterólogo em fusão com a flagelina de Salmonella buscou a expressão de um epitopo derivado da subunidade B da toxina colérica (Newton et al.,1989). As principais vantagens de se utilizar o sistema de expressão Salmonella/flagelina são: a) excluir seqüências de aminoácidos que possam desencadear respostas autoimunes indesejáveis; b) exposição dos epitopos heterólogos na superfície do flagelo em múltiplas cópias; c) promover reações imunoestimuladoras intrínsecas; d) promover a vetorização do antígeno heterólogo aos tecidos linfóides associados ao 
intestino (GALT) após administração por via oral de linhagens vivas atenuadas flageladas de Salmonella (Newton et al. , 1989, 1991, 1991a, 1995).

Evidências baseadas em modelos murinos indicam que respostas de anticorpos sistêmicos e secretados contra flagelina e epitopos heterólogos podem ser obtidos após imunização pela via oral (Wu et al., 1989, Brey et al., 1991). Entretanto, a maioria das pesquisas que descrevem a imunização de camundongos com linhagens atenuadas de Salmonella relata dificuldades na detecção de respostas de anticorpos sistêmicos e secretados direcionadas a epitopos fusionados à flagelina após imunização pela via oral (Brey et al., 1991; McEwen, 1992; Stocker \& Newton, 1994; Almeida et al., 1999; Sbrogio-Almeida e Ferreira, 2001).

A baixa imunogenicidade da flagelina FliCd expressa por linhagens atenuadas de S. Dublin, e epitopos a ela fusionados, em animais imunizados por vias de mucosas com linhagens vacinais bivalentes foi recentemente demonstrada (SbrogioAlmeida et al., 1999, Sbrogio-Almeida e Ferreira, 2001). No entanto, a constituição genética da linhagem bacteriana pode alterar a imunogenicidade da flagelina de Salmonella em modelo murino (Sbrogio-Almeida et al., 2004). S. Typhimurium representa uma esperança para o desenvolvimento de vacinas capazes de desencadear respostas de anticorpos contra flagelina e antígenos heterólogos após imunização pela via oral estudados em modelo murino.

Com a possibilidade de utilizar linhagens atenuadas de $S$. Typhimurium expressando flagelos híbridos pela via oral (Sbrogio-Almeida et al., 2004), torna-se interessante fusionar à flagelina epitopos de origem de patógenos entéricos, como estratégia para indução de resposta locais $(\lg A)$ conferindo proteção na porta de entrada de microrganismos causadores de doenças entéricas. Dois modelos de antígenos derivados de patógenos entéricos empregados em estratégias vacinais bivalente utilizando o sistema Salmonella-flagelina são o epitopo CTP3 da toxina colérica (CT) e a proteína CfaB da fímbria CFA/I de ETEC.

A CT desempenha papel fundamental na patogênese da cólera, representada por uma toxina do tipo $A B$, na qual a subunidade $B$ é o domínio responsável pela ligação ao receptor gangliosídico e A é a porção biologicamente ativa com atividade enzimática. A subunidade B da CT é composta por 103 aminoácidos, e promove a ligação da toxina aos receptores da membrana da célula alvo que contêm 0 gangliosídio $\mathrm{GM}_{1}$. Na toxina nativa a subunidade $\mathrm{B}$ está presente em 5 monômeros que vão promover o reconhecimento do receptor e auxiliar na internalização da 
subunidade A. A subunidade A catalisa a ADP-ribosilação da subunidade $\alpha$ da proteína $\mathrm{G}_{\mathrm{s}}$, levando ao aumento da atividade da adenilato ciclase e elevação do nível de AMP cíclico intracelular, resultando no desequilíbrio hidro-salino da célula, com secreção de eletrólitos e conseqüente perda de água para a luz intestinal (Sears \& Kaper, 1996).

O grupo de pesquisadores liderado por Ruth Arnon dividiu a subunidade $B$ da CT em 6 regiões, sintetizou os correspondentes peptídeos e estudou a capacidade de cada um deles em induzir anticorpos com atividade neutralizadora da ação biológica da toxina nativa (Jacob et al., 1983). O peptídeo denominado CTP-3, ligado covalentemente ao toxóide tetânico, foi o que induziu melhor resposta, dos seis peptídeos estudados. O peptídeo CTP-3, compreendendo os resíduos de 50 a 64 da subunidade $B$ da toxina colérica define um epitopo para linfócitos $B$ capaz de induzir anticorpos específicos e neutralizantes contra a toxina inteira (Jacob et al., 1983 e 1984, Newton et al., 1989). Os anticorpos gerados contra CTP-3 interagem com os resíduos Val, Pro, Gly, Gln, His e Asp do peptídeo, os quais equivalem respectivamente aos resíduos 50,53, 54, 56, 57 e 58 da subunidade $B$ da toxina, localizados em uma alça flexível próxima ao sítio de ligação ao receptor, o que explica sua eficácia como epitopo protetor (Spangler et al., 1992).

Os dois principais grupos de fatores de virulência expressos por linhagens de ETEC são as adesinas, em geral fimbriais, nomeadas fatores de colonização (CFAs) ou antígenos de superfície de E. coli (CS) ou fatores de colonização putativos (PCF), necessários à colonização do intestino delgado. O segundo grupo de fatores associados à virulência em ETEC é representado pelas toxinas, geralmente divididas em dois grupos: as toxinas termo-lábeis (LT) e as toxinas termo-estáveis (ST), responsáveis pela notável perda de eletrólitos e fluídos pelos enterócitos (Luna et al., 1997).

O CFA/I, o CFA/II e o CFA/IV são os CFs de ETEC mais freqüentes em estudos realizados em diferentes áreas geográficas e representam $50-80 \%$ dos CFs identificados em amostras de ETEC isoladas a partir de casos clínicos (Girón et al., 1995; López-Vidal et al., 1990). O CFA/l é uma das adesinas de ETEC com maior relevância epidemiológica, em particular na América do Sul (Binsztein et al., 1991; Guth et al., 1994). As subunidades da fímbria CFA/I possuem um arranjo helicoidal e, aparentemente, o sítio de interação da fímbria com o receptor na célula 
hospedeira está localizado na porção distal da fímbria (Evans et al., 1979; Bühler et al., 1991; Rudin et al., 1994; Gaastra \& Svennerholm, 1996).

Além das vantagens em se utilizar flagelinas híbridas expressas por linhagens vacinais há ainda uma série de vantagens no uso da flagelina como adjuvante de mucosa. Além da extraordinária ação estimuladora de resposta imune, a utilização da flagelina revela-se segura já que não foram observadas reações inflamatórias sistêmicas e que imunidade prévia à flagelina não interfere no potencial adjuvante permitindo que essa proteína possa ser empregada repetidas vezes mesmo na presença de uma imunidade prévia para a flagelina (Honko et al., 2006). Relatos da literatura demonstram que a atividade adjuvante das flagelinas está relacionada às regiões conservadas, uma vez que a utilização somente da região hipervariável não foi capaz de atuar como adjuvante. A administração nasal de flagelina é responsável, pelo menos em parte, pela potencialização das respostas humorais sistêmica e secretadas contra antígenos co-administrados, visto que essa via de administração permite uma rápida distribuição do antígeno a compartimentos sistêmicos e linfonodos drenantes (Lee et al., 2006). Estudos realizados com flagelinas oriundas de diferentes microrganismos como adjuvantes co-administrados demonstrou que ocorre preferencialmente a ativação de um padrão de resposta do tipo Th2, privilegiando o seu uso desta molécula na busca de vacinas contra patógenos que requerem esse tipo de resposta imunológica para uma eficiente proteção (Pino et al., 2005, Lee et al., 2006, Honko et al., 2006).

Com todas as propriedades relatadas, a flagelina torna-se um promissor alvo no estudo para o desenvolvimento de vacinas de mucosa, seja com a utilização de linhagens atenuadas capazes de expressar flagelina fusionada à antígenos heterólogos, administradas pela via oral, ou como proteína purificada coadministrada ou fusionada à antígenos heterólogos por via nasal. 


\section{CONCLUSÕES}

1. A capacidade de colonização e invasão de diferentes linhagens vacinais de $S$. Typhimurium capazes de expressar nenhum ou apenas um tipo flagelar (FliCi ou FljB) indica que a linhagem deficiente na expressão dos dois antígenos flagelares apresenta capacidade reduzida de colonizar o intestino e invadir o baço de camundongos BALB/c inoculados pela via oral;

2. Não foi possível estabelecer a imunogenicidade diferencial das flagelinas expressas por linhagens de $S$. Typhimurium em função da reversão dos alelos nativos de FliCi e FljB, nocauteados por transposons, durante crescimento in vivo da linhagem LDV $321^{\top}$ administrada pela via oral a camundongos BALB/c;

3. As respostas de anticorpos encontradas após administração oral com as linhagens de $S$. Typhimurium que expressam diferentes flagelinas, utilizando como controle negativo a linhagem não flagelada LDV321, são direcionadas a contaminantes presentes na preparação de flagelina purificada;

4. $\quad$ uso de promotores fortes para a expressão de flagelina pela linhagem vacinal LDV321 administrada pela via oral a camundongos não aumentou a resposta humoral à flagelina;

5. Os resultados obtidos com a administração de um reforço com flagelina purificada pela via nasal aos camundongos imunizados pela via oral com linhagem flagelada e não flagelada indica que pode haver uma supressão de resposta para flagelina administrada por vias de mucosa;

6. A ativação diferenciada de células $T$ pelas flagelinas $\mathrm{FliCi}$ e $\mathrm{FljB}$ de $S$. Typhimurium é dependente do tipo flagelar e da via de administração;

7. Não foi possível ativar respostas de anticorpos específicos a antígenos heterólogos em animais imunizados pela via oral com linhagens de $S$. Typhimurium que expressam a flagelina FliCi geneticamente fusionada a epitopos heterológos $\left(\right.$ CfaB $_{11-25}$ de ETEC e CTP3 da toxina colérica); 
8. Foi observado efeito adjuvante diferencial, tanto para respostas de anticorpos como para ativação de células $\mathrm{T}$, das diferentes flagelinas de Salmonella coadministradas a fímbria CFA/l ou fusionadas ao epitopo $\mathrm{CfaB}_{11-25}$ pela via intranasal. 
location of the receptor-binding site. Infect Immun. 1991; Nov;59(11):3876-82.

Carsiotis M, Weinstein D, Karch H, Holder I, O'Brien A. Flagella of Salmonella typhimurium are a virulence factor in infected C57BL/6J mice. Infect Immun. 1984; Dec;46(3):814-8.

Chatfield S, Roberts M, Li J, Starns A, Dougan G. The use of live attenuated Salmonella for oral vaccination. Dev Biol Stand. 1994; 82:35-42.

Chatfield SN, Strugnell RA, Dougan G. Live Salmonella as vaccines and carriers of foreign antigenic determinants. Vaccine. 1989; Dec;7(6):495-8.

Ciacci-Woolwine F, Blomfield IC, Richardson SH, Mizel SB. Salmonella flagellin induces tumor necrosis factor alpha in a human promonocytic cell line. Infect Immun. 1998; Mar;66(3):1127-34.

Ciacci-Woolwine F, McDermott P, Mizel S. Induction of cytokine synthesis by flagella from gram-negative bacteria may be dependent on the activation or differentiation state of human monocytes. Infect Immun. 1999; Oct;67(10):517685.

Cunningham AF, Khan M, Ball J, Toellner KM, Serre K, Mohr E, et al. Responses to the soluble flagellar protein FliC are Th2, while those to FliC on Salmonella are Th1. Eur J Immunol. 2004; Nov;34(11):2986-95.

Datsenko KA e Wanner BL. One-step inactivation of chromosomal genes in Escherichia coli K-12 using PCR products. Proc Natl Acad Sci U S A. 2000; Jun 6;97(12):6640-5.

Datta S, Redecke V, Prilliman K, Takabayashi K, Corr M, Tallant T, et al. A subset of Toll-like receptor ligands induces cross-presentation by bone marrow-derived dendritic cells. J Immunol. 2003; Apr;170(8):4102-10.

Davis RW, Botstein D, Roth JR, editors. Advanced bacterial genetics, Cold Spring Harbor Laboratory, Cold Spring Harbor, N.Y. 1980. p. 13-16.

de Vos T e Dick TA. A rapid method to determine the isotype and specificity of coproantibodies in mice infected with Trichinella or fed cholera toxin. J. Immunol. Methods. 1991; 141: 285-8. 
Didierlaurent A, Ferrero I, Otten LA, Dubois B, Reinhardt M, Carlsen H, et al. Flagellin promotes myeloid differentiation factor 88-dependent development of Th2-type response. J Immunol. 2004; Jun 1;172(11):6922-30.

Dogget TA e Brown PK. Attenuated Salmonella as vectors for oral immunization. In:Mucosal Vaccines, N. York, Academic Press. 1996:105-18.

Evans D, Evans DJ, Clegg S, Pauley J. Purification and characterization of the CFA/I antigen of enterotoxigenic Escherichia coli. Infect Immun. 1979; Aug;25(2):738-48.

Gaastra W, Svennerholm A. Colonization factors of human enterotoxigenic Escherichia coli (ETEC). Trends Microbiol. 1996; Nov;4(11):444-52.

Garmory H, Brown K, Titball R. Salmonella vaccines for use in humans: present and future perspectives. FEMS Microbiol Rev. 2002; Nov;26(4):339-53.

Gewirtz A, Simon PJ, Schmitt C, Taylor L, Hagedorn C, O'Brien A, et al. Salmonella typhimurium translocates flagellin across intestinal epithelia, inducing a proinflammatory response. J Clin Invest. 2001; Jan;107(1):99-109.

Girón J, Viboud G, Sperandio V, Gómez-Duarte O, Maneval D, Albert M, et al. Prevalence and association of the longus pilus structural gene (IngA) with colonization factor antigens, enterotoxin types, and serotypes of enterotoxigenic Escherichia coli. Infect Immun. 1995; Oct;63(10):4195-8.

Guth B, Aguiar E, Griffin P, Ramos S, Gomes T. Prevalence of colonization factor antigens (CFAs) and adherence to HeLa cells in enterotoxigenic Escherichia coli isolated from feces of children in São Paulo. Microbiol Immunol. 1994; 38(9):695701.

Hayashi F, Smith KD, Ozinsky A, Hawn TR, Yi EC, Goodlett DR, et al. The innate immune response to bacterial flagellin is mediated by Toll-like receptor 5. Nature. 2001; Apr 26;410(6832):1099-103.

He X, Rivkina M, Stocker B, Robinson W. Hypervariable region IV of Salmonella gene fliCd encodes a dominant surface epitope and a stabilizing factor for functional flagella. J Bacteriol. 1994; Apr;176(8):2406-14. 
Heithoff DM, Conner CP, Hentschel U, Govantes F, Hanna PC, Mahan MJ. Coordinate intracellular expression of Salmonella genes induced during infection. J Bacteriol. 1999; Feb;181(3):799-807.

Hess J, Kaufmann SH. Salmonella enterica infection. Res Immunol. 1996; OctDec;147(8-9):581-6.

Hoiseth SK, Stocker BA. Aromatic-dependent Salmonella typhimurium are nonvirulent and effective as live vaccines. Nature. 1981; May 21;291(5812):238-9.

Honko A, Mizel S. Effects of flagellin on innate and adaptive immunity. Immunol Res. 2005; 33(1):83-101.

Honko AN, Mizel SB. Mucosal administration of flagellin induces innate immunity in the mouse lung. Infect Immun. 2004; Nov;72(11):6676-9.

Honko AN, Sriranganathan N, Lees CJ, Mizel SB. Flagellin is an effective adjuvant for immunization against lethal respiratory challenge with Yersinia pestis. Infect Immun. 2006; Feb;74(2):1113-20.

Hormaeche CE. Live attenuated Salmonella vaccines and their potential as oral combined vaccines carrying heterologous antigens. J Immunol Methods. 1991; Aug 28;142(1):113-20.

Hughes K, Gillen K, Semon M, Karlinsey J. Sensing structural intermediates in bacterial flagellar assembly by export of a negative regulator. Science. 1993; Nov;262(5137):1277-80.

Huleatt J, Jacobs A, Tang J, Desai P, Kopp E, Huang Y, et al. Vaccination with recombinant fusion proteins incorporating Toll-like receptor ligands induces rapid cellular and humoral immunity. Vaccine. 2007; Jan;25(4):763-75.

Ikeda J, Schmitt C, Darnell S, Watson P, Bispham J, Wallis T, et al. Flagellar phase variation of Salmonella enterica serovar Typhimurium contributes to virulence in the murine typhoid infection model but does not influence Salmonellainduced enteropathogenesis. Infect Immun. 2001; May;69(5):3021-30.

Jacob C, Pines M, Arnon R. Neutralization of heat-labile toxin of E. coli by antibodies to synthetic peptides derived from the B subunit of cholera toxin. 
EMBO J. 1984; Dec;3(12):2889-93.

Jacob C, Sela M, Arnon R. Antibodies against synthetic peptides of the B subunit of cholera toxin: crossreaction and neutralization of the toxin. Proc Natl Acad Sci U S A. 1983; Dec;80(24):7611-5.

Jacob C, Sela M, Pines M, Hurwitz S, Arnon R. Both cholera toxin-induced adenylate cyclase activation and cholera toxin biological activity are inhibited by antibodies against related synthetic peptides. Proc Natl Acad Sci U S A. 1984; Dec;81(24):7893-6.

Jayaraman P, Peakman T, Busby S, Quincey R, Cole J. Location and sequence of the promoter of the gene for the $\mathrm{NADH}$-dependent nitrite reductase of Escherichia coli and its regulation by oxygen, the Fnr protein and nitrite. $\mathrm{J} \mathrm{Mol}$ Biol. 1987; Aug;196(4):781-8.

Joys T, Schödel F. Epitope mapping of the d flagellar antigen of Salmonella muenchen. Infect Immun. 1991; Sep;59(9):3330-2.

Joys T. Epitope mapping in Salmonella flagellar protein. SAAS Bull Biochem Biotechnol. 1991; Jan;4:56-9.

Joys TM. The covalent structure of the phase-1 flagellar filament protein of Salmonella typhimurium and its comparison with other flagellins. J Biol Chem. 1985; Dec 15;260(29):15758-61.

Koutsolioutsou A, Martins E, White D, Levy S, Demple B. A soxRS-constitutive mutation contributing to antibiotic resistance in a clinical isolate of Salmonella enterica (Serovar Typhimurium). Antimicrob Agents Chemother. 2001; Jan;45(1):38-43.

Lee SE, Kim SY, Jeong BC, Kim YR, Bae SJ, Ahn OS, et al. A bacterial flagellin, Vibrio vulnificus FlaB, has a strong mucosal adjuvant activity to induce protective immunity. Infect Immun. 2006; Jan;74(1):694-702.

Lien E, Golenbock D. Adjuvants and their signaling pathways: beyond TLRs. Nat Immunol. 2003; Dec;4(12):1162-4.

Liochev S, Fridovich I. Fumarase C, the stable fumarase of Escherichia coli, is controlled by the soxRS regulon. Proc Natl Acad Sci U S A. 1992; Jul;89(13):5892-6. 
López-Vidal Y, Calva J, Trujillo A, Ponce de León A, Ramos A, Svennerholm A, et al. Enterotoxins and adhesins of enterotoxigenic Escherichia coli: are they risk factors for acute diarrhea in the community? J Infect Dis. 1990; Aug;162(2):442-7.

Luna MG, Martins MM, Newton SM, Costa SO, Almeida DF, Ferreira LC. Cloning and expression of colonization factor antigen I (CFA/I) epitopes of enterotoxigenic Escherichia coli (ETEC) in Salmonella flagellin. Res Microbiol. 1997; MarApr;148(3):217-28.

Manganaro M, Ogra PL, Ernst PB. Oral immunization: turning fantasy into reality. Int Arch Allergy Immunol. 1994; 103(3):223-33.

Marciani D. Vaccine adjuvants: role and mechanisms of action in vaccine immunogenicity. Drug Discov Today. 2003; Oct;8(20):934-43.

Martin M, Wesche $\mathrm{H}$. Summary and comparison of the signaling mechanisms of the Toll/interleukin-1 receptor family. Biochim Biophys Acta. 2002; Nov;1592(3):265-80.

McEwen J, Levi R, Horwitz RJ, Arnon R. Synthetic recombinant vaccine expressing influenza haemagglutinin epitope in Salmonella flagellin leads to partial protection in mice. Vaccine. 1992; 10(6):405-11.

McSorley S, Xu D, Liew F. Vaccine efficacy of Salmonella strains expressing glycoprotein 63 with different promoters. Infect Immun. 1997; Jan;65(1):171-8.

McSorley SJ, Cookson BT, Jenkins MK. Characterization of CD4+ T cell responses during natural infection with Salmonella typhimurium. J Immunol. 2000; Jan 15;164(2):986-93.

Means T, Hayashi F, Smith K, Aderem A, Luster A. The Toll-like receptor 5 stimulus bacterial flagellin induces maturation and chemokine production in human dendritic cells. J Immunol. 2003; May;170(10):5165-75.

Michalek S, Katz J, Childers N, Martin M, Balkovetz D. Microbial/host interactions: mechanisms involved in host responses to microbial antigens. Immunol Res. 2002; 26(1-3):223-34. 
Mizel S, Honko A, Moors M, Smith P, West A. Induction of macrophage nitric oxide production by Gram-negative flagellin involves signaling via heteromeric Toll-like receptor 5/Toll-like receptor 4 complexes. J Immunol. 2003; Jun;170(12):6217-23.

Muzio M, Polntarutti N, Bosisio D, Prahladan M, Mantovani A. Toll like receptor family (TLT) and signalling pathway. Eur Cytokine Netw. 2000; Sep;11(3):489-90.

Neutra MR, Frey A, Kraehenbuhl JP. Epithelial M cells: gateways for mucosal infection and immunization. Cell. 1996; Aug 9;86(3):345-8.

Newton S, Joys T, Anderson S, Kennedy R, Hovi M, Stocker B. Expression and immunogenicity of an 18-residue epitope of HIV1 gp41 inserted in the flagellar protein of a Salmonella live vaccine. Res Microbiol. 1995a; Mar-Apr;146(3):20316.

Newton S, Klebba P, Hofnung M, Charbit A. Studies of the anaerobically induced promoter pnirB and the improved expression of bacterial antigens. Res Microbiol. 1995; Mar-Apr;146(3):193-202.

Newton SM, Jacob CO, Stocker BA. Immune response to cholera toxin epitope inserted in Salmonella flagellin. Science. 1989; Apr 7;244(4900):70-2.

Newton SM, Kotb M, Poirier TP, Stocker BA, Beachey EH. Expression and immunogenicity of a streptococcal $M$ protein epitope inserted in Salmonella flagellin. Infect Immun. 1991; Jun;59(6):2158-65.

Newton SM, Wasley RD, Wilson A, Rosenberg LT, Miller JF, Stocker BA. Segment IV of a Salmonella flagellin gene specifies flagellar antigen epitopes. Mol Microbiol. 1991a; Feb;5(2):419-25.

Peakman T, Busby S, Cole J. Transcriptional control of the cysG gene of Escherichia coli K-12 during aerobic and anaerobic growth. Eur J Biochem. 1990; Jul;191(2):325-31.

Pino O, Martin M, Michalek SM. Cellular mechanisms of the adjuvant activity of the flagellin component FljB of Salmonella enterica Serovar Typhimurium to potentiate mucosal and systemic responses. Infect Immun. 2005; Oct;73(10):6763-70. 
Ramos HC, Rumbo M, Sirard JC. Bacterial flagellins: mediators of pathogenicity and host immune responses in mucosa. Trends Microbiol. 2004; Nov;12(11):50917.

Rudin A, McConnell M, Svennerholm A. Monoclonal antibodies against enterotoxigenic Escherichia coli colonization factor antigen I (CFA/I) that crossreact immunologically with heterologous CFAs. Infect Immun. 1994; Oct;62(10):4339-46.

Sambrook, J., Fritsh, E. e Maniatis, T. Molecular cloning: a laboratory manual. $2^{\text {nd }}$ edition, Cold Spring, Cold Spring Harbor Laboratory Press, N. York, 1989.

Savidge TC. The life and times of an intestinal M cell. Trends Microbiol. 1996; Aug;4(8):301-6.

Sbrogio-Almeida ME, Ferreira LC. Flagellin expressed by live Salmonella vaccine strains induces distinct antibody responses following delivery via systemic or mucosal immunization routes. FEMS Immunol Med Microbiol. 2001; Apr;30(3):203-8.

Sbrogio-Almeida ME, Mosca T, Massis LM, Abrahamsohn IA, Ferreira LC. Host and bacterial factors affecting induction of immune responses to flagellin expressed by attenuated Salmonella vaccine strains. Infect Immun. 2004; May;72(5):2546-55.

Schmitt C, Darnell S, O'Brien A. The attenuated phenotype of a Salmonella typhimurium flgM mutant is related to expression of FliC flagellin. J Bacteriol. 1996; May;178(10):2911-5.

Sears C, Kaper J. Enteric bacterial toxins: mechanisms of action and linkage to intestinal secretion. Microbiol Rev. 1996; Mar;60(1):167-215.

Siebers A, Finlay BB. M cells and the pathogenesis of mucosal and systemic infections. Trends Microbiol. 1996; Jan;4(1):22-9.

Slauch J, Taylor R, Maloy S. Survival in a cruel world: how Vibrio cholerae and Salmonella respond to an unwilling host. Genes Dev. 1997; Jul 15;11(14):176174. 
Smith KD, Ozinsky A. Toll-like receptor-5 and the innate immune response to bacterial flagellin. Curr Top Microbiol Immunol. 2002; 270:93-108.

Spangler B. Structure and function of cholera toxin and the related Escherichia coli heat-labile enterotoxin. Microbiol Rev. 1992; Dec;56(4):622-47.

Stocker BA, Newton SM. Immune responses to epitopes inserted in Salmonella flagellin. Int Rev Immunol. 1994; 11(2):167-78.

Stocker BA. Aromatic-dependent Salmonella as live vaccine presenters of foreign epitopes as inserts in flagellin. Res Microbiol. 1990; Sep-Oct;141(7-8):787-96.

Takeda K, Kaisho T, Akira S. Toll-like receptors. Annu Rev Immunol. 2003; 21:335-76.

Tsujimoto H, Ono S, Majima T, Kawarabayashi N, Takayama E, Kinoshita M, et al. Neutrophil elastase, MIP-2, and TLR-4 expression during human and experimental sepsis. Shock. 2005; Jan;23(1):39-44.

Wei LN, Joys TM. Covalent structure of three phase- 1 flagellar filament proteins of Salmonella. J Mol Biol. 1985; Dec 20;186(4):791-803.

Weinstein D, Carsiotis M, Lissner C, O'Brien A. Flagella help Salmonella typhimurium survive within murine macrophages. Infect Immun. 1984; Dec;46(3):819-25.

Weinstein DL, O'Neill BL, Hone DM, Metcalf ES. Differential early interactions between Salmonella enterica serovar Typhi and two other pathogenic Salmonella serovars with intestinal epithelial cells. Infect Immun. 1998; May;66(5):2310-8.

Wilson D, Beveridge T. Bacterial flagellar filaments and their component flagellins. Can J Microbiol. 1993; May;39(5):451-72.

Wu JY, Newton S, Judd A, Stocker B, Robinson WS. Expression of immunogenic epitopes of hepatitis $B$ surface antigen with hybrid flagellin proteins by a vaccine strain of Salmonella. Proc Natl Acad Sci U S A. 1989; Jun;86(12):4726-30.

Yonekura K, Maki-Yonekura S, Namba K. Complete atomic model of the bacterial flagellar filament by electron cryomicroscopy. Nature. 2003; 424(6949):643-50. 


\section{REFERÊNCIAS BIBLIOGRÁFICAS}

Acero-Reyes, JR e Newton, SMC. Expression of cholera toxin epitopes inserted in flagellin by attenuated Salmonella strains. Rev. Brasil. Genet. 1994; 17: 249254.

Aizawa S, Vonderviszt F, Ishima R, Akasaka K. Termini of Salmonella flagellin are disordered and become organized upon polymerization into flagellar filament. J Mol Biol. 1990; Feb;211(4):673-7.

Almeida ME, Newton SM, Ferreira LC. Antibody responses against flagellin in mice orally immunized with attenuated Salmonella vaccine strains. Arch Microbiol. 1999; Aug;172(2):102-8.

Basset C, Holton J, O'Mahony R, Roitt I. Innate immunity and pathogen-host interaction. Vaccine. 2003; Jun;21 Suppl 2:S12-23.

Baumler AJ. The record of horizontal gene transfer in Salmonella. Trends Microbiol. 1997; Aug;5(8):318-22.

Ben-Yedidia T, Arnon R. Effect of pre-existing carrier immunity on the efficacy of synthetic influenza vaccine. Immunol Lett. 1998; Nov;64(1):9-15.

Binsztein N, Jouve M, Viboud G, López Moral L, Rivas M, Orskov I, et al. Colonization factors of enterotoxigenic Escherichia coli isolated from children with diarrhea in Argentina. J Clin Microbiol. 1991; Sep;29(9):1893-8.

Bonifield HR, Hughes KT. Flagellar phase variation in Salmonella enterica is mediated by a posttranscriptional control mechanism. J Bacteriol. 2003; Jun;185(12):3567-74.

Brenner FW, Villar RG, Angulo FJ, Tauxe R, Swaminathan B. Salmonella nomenclature. J Clin Microbiol. 2000; Jul;38(7):2465-7.

Brey RN, Bixler GS, Fulginiti JP, Dilts DA, Sabara MI. Oral delivery of antigens in live bacterial vectors. Adv Exp Med Biol. 1991; 303:169-84.

Bühler $\mathrm{T}$, Hoschützky $\mathrm{H}$, Jann $\mathrm{K}$. Analysis of colonization factor antigen I, an adhesin of enterotoxigenic Escherichia coli O78:H11: fimbrial morphology and 